\title{
Preeclamptic sera induce nephrin shedding from podocytes through endothelin-1 release by endothelial glomerular cells
}

\author{
Federica Collino, ${ }^{1 *}$ Benedetta Bussolati, ${ }^{1 *}$ Elisa Gerbaudo, ${ }^{1}$ Luca Marozio, ${ }^{2}$ Simona Pelissetto, ${ }^{2}$ \\ Chiara Benedetto, ${ }^{2}$ and Giovanni Camussi ${ }^{1}$ \\ ${ }^{1}$ Department of Internal Medicine, Research Centre for Experimental Medicine and Molecular Biotechnology Center, \\ and ${ }^{2}$ Department of Gynaecology and Obstetrics, University of Torino, Torino, Italy
}

Submitted 21 September 2007; accepted in final form 15 February 2008

\begin{abstract}
Collino F, Bussolati B, Gerbaudo E, Marozio L, Pelissetto S, Benedetto C, Camussi G. Preeclamptic sera induce nephrin shedding from podocytes through endothelin-1 release by endothelial glomerular cells. Am J Physiol Renal Physiol 294: F1185-F1194, 2008. First published February 20, 2008; doi:10.1152/ajprenal.00442.2007.-In preeclampsia $(\mathrm{PE})$, proteinuria has been associated with a reduced expression of nephrin by podocytes. In the present study, we investigated in vitro on human cultured podocytes the mechanism responsible for nephrin loss in PE. Sera from patients with PE did not directly downregulate the expression of nephrin. In contrast, conditioned medium obtained from glomerular endothelial cells incubated with PE sera induced loss of nephrin and synaptopodin, but not of podocin, from podocytes. Nephrin loss was related to a rapid shedding of the protein from the cell surface due to cleavage of its extracellular domain by proteases and to cytoskeleton redistribution. The absence of nephrin mRNA downregulation together with nephrin reexpression within $24 \mathrm{~h}$ confirm that the loss of nephrin was not related to a reduced synthesis. Studies with an endothelin-1 (ET-1) receptor antagonist that abrogated the loss of nephrin triggered by glomerular endothelial conditioned medium of PE sera indicated that ET-1 was the main effector of nephrin loss. Indeed, ET-1 was synthesized and released from glomerular endothelial cells when incubated with PE sera, and recombinant ET-1 triggered nephrin shedding from podocytes. Moreover, VEGF blockade induced ET-1 release from endothelial cells, and in turn the conditioned medium obtained triggered nephrin loss. In conclusion, the present study identifies a potential mechanism of nephrin loss in PE that may link endothelial injury with enhanced glomerular permeability.
\end{abstract}

slit diaphragm; synaptopodin; proteinuria; VEGF blockade

PREECLAMPSIA (PE) affects 1\%-8\% of all first pregnancies. The maternal syndrome is characterized by elevated blood pressure, proteinuria, and damage of different organ systems including the liver, kidney, brain, heart, and lungs. The systemic features can vary from mild cases with little systemic involvement to multiorgan failure. In $30 \%$ of the cases, the disease may cause placental insufficiency, leading to intrauterine growth restriction or fetal death. (46).

Defective remodeling of the spiral arteries at the time of trophoblast invasion is the most widely recognized predisposing factor for PE. As a result, perfusion of the intervillous space is impaired, leading to placental hypoxia (34). Several data support the theory that $\mathrm{PE}$ is the result of a generalized endothelial injury and dysfunction, due to the release of different placental factors $(7,17,32,38)$. Among those factors, an

* F. Collino and B. Bussolati contributed equally to this work.

Address for reprint requests and other correspondence: G. Camussi, Cattedra di Nefrologia, Dipartimento di Medicina Interna, Ospedale Maggiore S Giovanni Battista, Corso Dogliotti 14, 10126, Torino, Italy (e-mail: giovanni. camussi@unito.it). increase in PE sera of fibronectin, factor VIII antigen and thrombomodulin has been reported, all markers of vascular dysfunction $(35,42)$ Recently, it has been observed that serum levels of soluble vascular endothelial growth factor (VEGF) receptor-1 (sFlt1), a circulating antagonist of VEGF, were elevated in women with PE (45).

sFlt1 is a splice variant of VEGF receptor-1, which lacks the cytoplasmic and transmembrane domain, but retains the ligand-binding domain $(18,22)$. However, it is at present unknown whether sFlt1 and/or other circulating factors in PE induce proteinuria by a direct effect or rather by an indirect effect involving the local release of factors affecting podocytes.

It has been recently shown that slit diaphragm proteins of podocytes play a critical role in the maintenance of glomerular permeability. In particular, nephrin, a transmembrane protein of the Ig superfamily, expressed in the slit diaphragm between the podocyte foot processes, is involved in the maintenance of slit pore integrity and renal filtration capacity. The pivotal role of nephrin in the regulation of glomerular filter integrity has recently emerged from genetic studies showing that mutations in the nephrin gene (NPHS1) underline the development of the congenital nephritic syndrome of the Finnish type $(23,24)$. Several studies have provided evidence that nephrin associates with itself, forming a zipper-like structure that acts as a sizeand charge-selective filtration barrier. Moreover, nephrin has been demonstrated to have signaling functions, enabled by the intracellular domain with nine tyrosine residues, regulating podocyte cell polarity, cell survival, and cytoskeletal organization (15). The role of nephrin in proteinuria developing in PE has been confirmed by a recent report showing a reduction in the expression of nephrin and synaptopodin in glomeruli of PE patients (13).

The aim of the present study was to investigate whether sera from PE patients may downregulate the expression of nephrin from podocytes either directly or as a consequence of glomerular endothelial cell activation.

\section{MATERIALS AND METHODS}

Reagents. Polyclonal anti-nephrin guinea pig antibodies to the extracellular fibronectin domain (GP-N1) and to the intracellular domain (GP-N2) and monoclonal anti-synaptopodin mouse antibody were all purchased from Progen Biotechnik (Heidelberg, Germany). Goat polyclonal anti-podocin and anti-nephrin antibodies and antinephrin blocking peptide were purchased from Santa Cruz Biotech-

\footnotetext{
The costs of publication of this article were defrayed in part by the payment of page charges. The article must therefore be hereby marked "advertisement" in accordance with 18 U.S.C. Section 1734 solely to indicate this fact.
} 
nology (Heidelberg, Germany). FCS was from Euroclone (Wetherby, West Yorkshire, UK). DMEM, BSA fraction V (tested for not more than $1 \mathrm{ng}$ endotoxin/mg), human ET-1, $N$-acetyl-[D-TRP $\left.{ }^{16}\right]$-ET1, fragments 16-21 (ET-1A receptor antagonist), FITC-phalloidin, TRI reagent, Hoechst 33258 dye, $\alpha_{1}$-anti-trypsin, anti-PI, and FITC antiguinea pig secondary antibody were obtained from Sigma (St. Louis, MO). Alexa Fluor 488 anti-goat or anti-guinea pig and Texas red anti-mouse IgG were supplied by Molecular Probes (Leiden, The Netherlands). GM6001 and SB-3CT were purchased from Chemicon International (Temecula, CA). The angiotensin II receptor (AT1A) antagonist losartan, or DuP753 (2-n-butyl-4-chloro-5-hydroxymethyl1-[2-(1H-tetrazole-5-yl) biphenyl-4-hy] methyl) imidazole, was kindly provided by Dr. Gabriella Gruden (University of Torino) and was supplied by DuPont Merck (West Point, PA). Human anti-VEGF polyclonal antibody was obtained from R\&D Systems (Minneapolis, MN).

Patients. PE was diagnosed in the presence of two consecutive blood pressure measurements of $>140 \mathrm{mmHg}$ systolic or $>90 \mathrm{mmHg}$ diastolic and proteinuria ( $\geq 300 \mathrm{mg}$ in one 24 -h urine collection) after week 20 of pregnancy in a previously normotensive and nonproteinuric woman $(1,31,36)$. Healthy, normotensive pregnant women were included as controls (Table 1). Approval of the study was obtained from the Center for Molecular Biotechnology Institutional Review Board, University of Torino. Patients with chronic hypertension, preexisting proteinuria, or renal disease were excluded from the study. Blood samples were collected from pregnant patients at the time of the diagnosis of PE, after informed consent was obtained. Maternal age, parity, gestational age at delivery, birth weight, placental weight, blood pressure values, urinary protein excretion, serum creatinine, and serum uric acid levels were recorded for each patient included in the study.

Cell lines. Primary microvascular endothelial cell lines obtained from renal glomeruli were prepared. Briefly, human glomeruli were purified from specimens of normal renal tissue obtained for polar carcinomas by passages on sequential meshes, digested by trypsin $\left(0.1 \%, 30 \mathrm{~min}\right.$. at $\left.37^{\circ} \mathrm{C}\right)$, and plated onto gelatin in EBM complete medium. After $1 \mathrm{wk}$, cells were detached and endothelial cells were purified by using an anti-CD31 antibody coupled to magnetic beads by magnetic cell sorting using the MACS system (Miltenyi Biotec, Auburn, CA). Cells were characterized by morphology and expression of a panel of endothelial antigens, as described elsewhere (4).

Primary cultures of human podocytes were established, and lines of differentiated podocytes were obtained by infection with a hybrid Adeno5/SV40 virus. Podocytes were characterized for the positive expression of nephrin, podocin, and synaptopodin and for negative expression of von Willebrand factor, CD31, and smooth muscle cell actin, as previously described (6). Cells were cultured in DMEM containing 4,500 mg/l glucose with $10 \%$ FCS.

Experimental conditions. For immunofluorescence (IF) studies, podocytes were plated on eight-well Permanox slides at a density of 50,000 cells/well. For fluorescence-activated cell sorting (FACS) analysis, podocytes were plated in a 12 -well tissue culture plate at subconfluent density. The following day, cell layers were rinsed with

Table 1. Clinical characteristics of patients

\begin{tabular}{lcc}
\hline \hline & PE $(n=20)$ & Normal $(n=20)$ \\
\hline Maternal age, yr & $30.9 \pm 4$ & $30.6 \pm 6$ \\
Primigravida & 15 & 11 \\
Gestational age at delivery, wk & $33.9 \pm 3^{*}$ & $39.7 \pm 1$ \\
Birth weight of child, g & $2,166.8 \pm 823^{*}$ & $3,383 \pm 432$ \\
Placental weight, g & $441.3 \pm 127^{*}$ & $587.25 \pm 97$ \\
Urinary protein, g/24 h & $1.98 \pm 1.6^{*}$ & $0.102 \pm 0.1$ \\
Serum creatinine, mg/dl & $0.77 \pm 0.3$ & $0.72 \pm 0.1$ \\
Serum uric acid, $\mathrm{mg} / \mathrm{dl}$ & $6.17 \pm 1.8^{*}$ & $4.3 \pm 1.1$
\end{tabular}

Values are means \pm SD of 20 patients with preeclampsia (PE) and 20 normal pregnant women. ${ }^{*} P<0.005$.
PBS. Podocytes were starved for $1 \mathrm{~h}$ and then incubated with serum derived from PE and normal women (1:10 dilution) for different times before fixation and staining with an anti-nephrin polyclonal antibody.

In other experiments, glomerular endothelial cells were incubated in the presence of PE or normal serum or plasma $(1: 10)$ or with an anti-VEGF antibody $(4.5 \mu \mathrm{g} / \mathrm{ml})$ for $72 \mathrm{~h}$. The obtained endothelial conditioned medium (ECM) was used (1:10 dilution) to stimulate podocytes for $1 \mathrm{~h}$ to assess nephrin, podocin, and synaptopodin expression. In time course experiments, podocytes were stimulated for $20 \mathrm{~min}, 1 \mathrm{~h}$, or $24 \mathrm{~h}$.

In selected experiments, ET-1A and AT1A receptor antagonists $\left(N\right.$-acetyl-[D-TRP ${ }^{16}$ ]-ET1, fragment $16-21,0.4 \mu \mathrm{M}$; losartan, $10^{-6}$ $\mathrm{M})$ were added to the cells $1 \mathrm{~h}$ before ECM stimulation.

In addition, in some experiments podocytes were incubated with the generic protease inhibitor PMSF (1 mmol) or with two specific serine protease inhibitors, $\alpha_{1}$-anti-trypsin $(5 \mu \mathrm{g} / \mathrm{ml})$ and anti-PI (5-10 $\mu \mathrm{g} / \mathrm{ml}$ ) for $20 \mathrm{~min}$ before ECM treatment or with two specific MMP inhibitors, GM6001 (15 $\mathrm{nM})$ and SB-3CT $(4 \mu \mathrm{M})$, during ECM stimulation.

In other experiments, podocytes were incubated in the presence of human ET-1 (10 nM) (30) for $1 \mathrm{~h}$ before detection of nephrin by FACS analysis. For evaluating actin microfilament alterations in PE-stimulated podocytes, cells were incubated with ECM for $1 \mathrm{~h}$ and then fixed, permeabilized, and stained with FITC-phalloidin.

Detection of nephrin, podocin, and synaptopodin expression by immunofluorescence and flow cytometric studies. Immunofluorescence on cultured podocytes was performed as described previously (3). Cells were fixed in $3.5 \%$ paraformaldehyde containing $2 \%$ sucrose for $15 \mathrm{~min}$ at $4^{\circ} \mathrm{C}$ and, when needed, permeabilized with HEPES-Triton X-100 buffer (Sigma). Guinea pig anti-nephrin (GP$\mathrm{N} 1$, diluted 1:50), goat anti-podocin (1:50), or mouse anti-synaptopodin (undiluted) primary antibodies were applied on the cells for $1 \mathrm{~h}$ at $4^{\circ} \mathrm{C}$. Cells were washed and subsequently incubated with fluorescein isothiocyanate or rhodamine-conjugated anti-guinea pig, goat, or mouse IgG secondary antibodies (Molecular Probes) for $1 \mathrm{~h}$ at room temperature. Secondary antibodies alone were used in all experiments as controls. Nephrin, synaptopodin, and podocin expression on cultured podocytes was analyzed semiquantitatively by measuring fluorescence intensity by digital image analysis (Windows Micro Image, CASTI Imaging, Venice, Italy) on images obtained using a low-light video camera (Leica DC100) on $\times 400$ microscopic fields as described elsewhere (11). Membrane localization of slit diaphragm proteins was analyzed by confocal microscopy using a Zeiss LSM 5 Pascal model confocal microscope (Carl Zeiss, Oberkochen, Germany). Hoechst 33258 dye (Sigma) was added for nuclear staining. For flow cytometric analyses, podocytes were collected with nonenzymatic cell dissociation solution, fixed with $4 \%$ paraformaldehyde for $15 \mathrm{~min}$, and stained for $1 \mathrm{~h}$ at $4^{\circ} \mathrm{C}$ with guinea pig anti-nephrin polyclonal antibody (final dilution 1:50) or corresponding isotype antibody, washed, and incubated with FITC-conjugated anti-guinea pig IgG for $1 \mathrm{~h}$ at $4^{\circ} \mathrm{C}$.

Immunoprecipitation and Western blot analysis. Proteins of podocytes were extracted with a cold lysis buffer $(50 \mathrm{mmol}$ Tris $\cdot \mathrm{HCl}, \mathrm{pH}$ 8.3 , containing $1 \%$ Triton X-100, 1 mmol PMSF, $2 \mu \mathrm{g} / \mathrm{ml}$ leupeptin, $2 \mu \mathrm{g} / \mathrm{ml}$ aprotinin, and $2 \mathrm{mmol}$ sodium orthovanadate) at $4^{\circ} \mathrm{C}$ for $1 \mathrm{~h}$ and centrifuged at $15,000 \mathrm{~g}$ for $15 \mathrm{~min}$. For the detection of nephrin, which is contained within lipid raft microdomains, the lysis buffer was supplemented with $20 \mathrm{mmol} 3$-[(3-cholamidopropyl)-dimethilammonio]-1-propanesulfonate (Sigma).

Immunoprecipitation with an anti-nephrin $\mathrm{IgG}$ polyclonal antibody cross-linked to Sepharose-protein A was performed as described by (8). Electrophoresis of the immunoprecipitates was performed as described previously (8).

For Western blot analysis, podocyte-free supernatants were concentrated, and $100 \mu \mathrm{g}$ of proteins from cell lysates and cell-free supernatants were separated on $8 \%$ SDS-PAGE and transferred to nitrocellulose membranes (Bio-Rad, Hercules, CA). Membranes were 
A
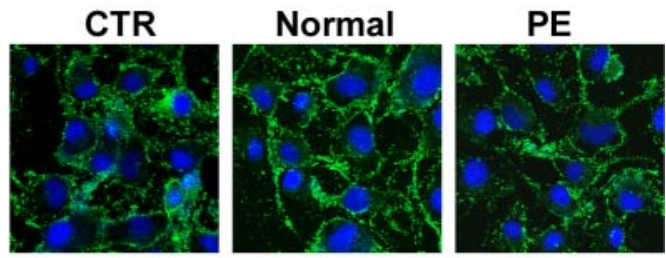

B

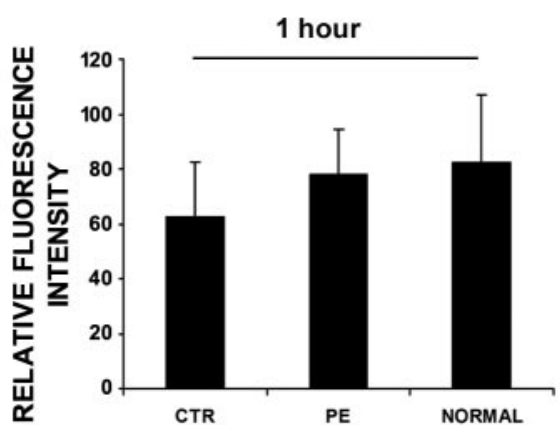

C

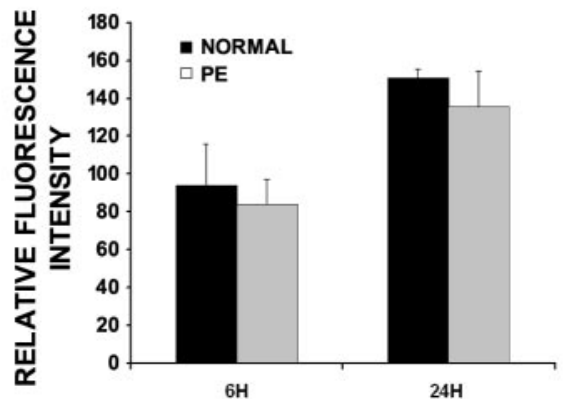

Fig. 1. Direct effect of preeclampsia (PE) sera on nephrin expression by human podocytes. A: representative micrographs of nephrin expression detected by immunofluorescence using an antibody specific for the nephrin extracellular domain in podocytes incubated for $1 \mathrm{~h}$ with medium alone (CTR), sera from normal pregnant women (NORMAL), or sera from women with PE. Different stimuli did not modify nephrin expression. Original magnification $\times 400 . B$ and $C$ : semiquantitative analysis of nephrin expression evaluated as relative fluorescence intensity (see MATERIALS AND METHODS) after cell stimulation for $1(B)$ or for 6 and $24 \mathrm{~h}(C)$ showing the absence of significant variations. The incubation with sera did not modify cell viability, as detected by trypan blue dye exclusion at the different times studied. Values are means \pm SD of 10 different sera for each experimental condition. CTR, control.

labeled with two different antibodies against nephrin extracellular domain (GP-N1 and N-20) and an antibody against the intracellular domain (GP-N2) at $4^{\circ} \mathrm{C}$ overnight. In selected experiments, the anti-nephrin polyclonal antibody $\mathrm{N}-20$ was preincubated with a blocking peptide (1:5 ratio, antibody to peptide) for $3 \mathrm{~h}$ at room temperature before membrane labeling. Blots were probed with horseradish peroxidase-conjugated protein A (Amersham, Little Chalfont, UK) or anti-goat secondary antibody (DakoCytomation, Copenhagen, Denmark) for $1 \mathrm{~h}$ at room temperature and developed with chemiluminescence reagents (ECL; Amersham) (48).

Enzyme-linked immunosorbent assay. Enzyme-linked immunosorbent assay (ELISA) for human ET-1 was obtained from Cayman Chemical (Ann Arbor, MI) and performed according to the manufacturer's specifications. Aliquots of supernatants from glomerular endothelial cells untreated or treated with PE and "normal" serum or with blocking anti-VEGF antibody were assayed in triplicate.

Quantitative real-time PCR. Quantitative RT-PCR was performed as described previously (28). Relative quantization by real-time PCR was performed using SYBR-green detection of PCR products in real time using the 48-well StepOne Real Time System (Applied Biosystems, Foster City, CA). Sequence-specific oligonucleotide primers (purchased from MWG-Biotech, Ebersberg, Germany) were the following: human nephrin: forward, 5'-CAC GGT CAG CAC AAC AGA GG-3' and reverse, 5'-GAA ACC TCG GGA ATA AGA CAC CT-3'; human GAPDH: forward, 5'-TGG AAG GAC TCA TGA CCA CAG T-3' and reverse, 5'-CAT CAC GCC ACA GTT TCC C-3'; and human ET-1: forward, 5'-AAC CAG GTC GGA GAC CAT GA-3' and reverse, 5'-CCG AAG GTC TGT CAC CAA TGT-3'. Power SYBR Green PCR Master Mix was purchased from Applied Biosystems. Thermal cycling conditions were as follows: activation of AmpliTaq Gold DNA Polymerase LD at $95^{\circ} \mathrm{C}$ for $10 \mathrm{~min}$, followed by 50 cycles of amplification at $95^{\circ} \mathrm{C}$ for $15 \mathrm{~s}, 60^{\circ} \mathrm{C}$ (for nephrin, ET-1, and GAPDH) for $1 \mathrm{~min}$. To detect the log phase of amplification, the fluorescence level (quantification of product) was determined at each cycle. The cycle at which the fluorescence reached threshold was recorded, averaged between triplicates, and normalized to the averaged cycle of threshold value for GAPDH. The fold-change in expression with respect to control (unstimulated cells) was calculated for all samples.

A

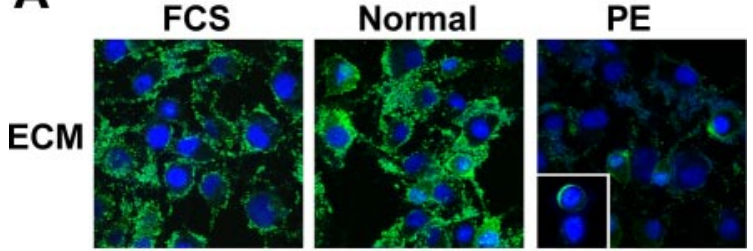

B
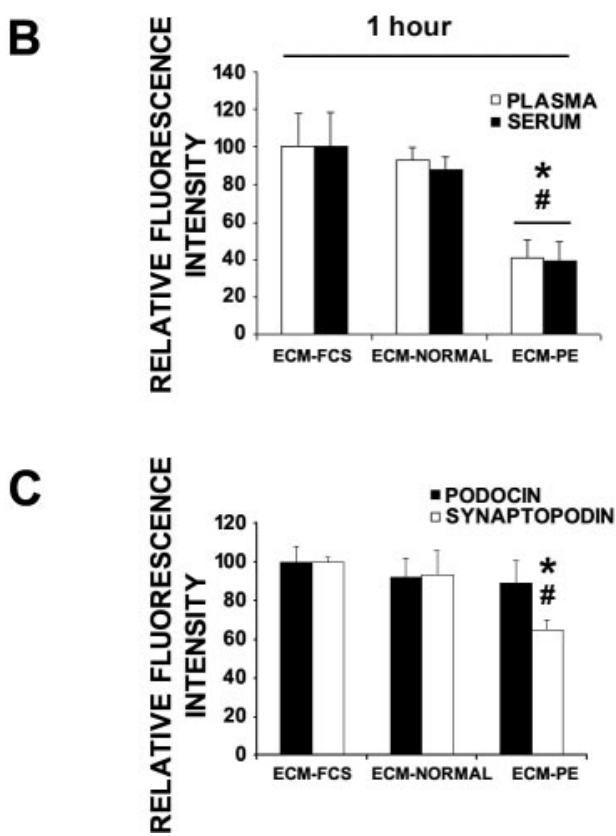

Fig. 2. Indirect effect of PE sera on nephrin expression by human podocytes $A$ : representative micrographs of nephrin expression detected by immunofluorescence in podocytes incubated with endothelial conditioned medium (ECM) derived from glomerular endothelial cells stimulated with medium alone (ECM-FCS) or with sera from normal pregnant women (ECM-NORMAL) or of women with PE (ECM-PE). ECM-PE induced a marked reduction of nephrin expression on the podocyte surface compared with ECM-FCS or ECM-NORMAL, with a protein redistribution as aspect of capping (inset). Original magnification $\times 400$. $B$ : semiquantitative analysis of nephrin expression evaluated as relative fluorescence intensity (see MATERIALS AND METHODS) after cell stimulation with ECM for $1 \mathrm{~h}$. Values are means \pm SD of 20 different sera (filled bars) or of 10 different plasmas (open bars) for each experimental condition. $C$ : semiquantitative analysis of podocin and synaptopodin expression evaluated as relative fluorescence intensity after cell stimulation with ECM for $1 \mathrm{~h}$. Values are means $\pm \mathrm{SD}$ of 10 different plasmas for each experimental condition. $* P<0.05$ vs. control. $\# P<0.05$ vs. ECM-NORMAL. 
Statistical analysis. Results are representative of at least three independent experiments performed in triplicate and are expressed as means \pm SD. Statistical analysis of the data was performed using Student's $t$-test. Significant differences are reported when $P<0.05$.

\section{RESULTS}

Effects of sera from PE or normal pregnant women on nephrin expression by podocytes. It has been shown that the glomerular expression of nephrin is reduced in patients with PE (13). We evaluated whether serum factors may directly account for the reduced nephrin expression. The expression of nephrin was evaluated on human cultured podocytes stimulated with sera of PE patients and normal pregnant women. Podocytes were incu- bated for 1,6 , or $24 \mathrm{~h}$ with $10 \%$ serum from PE or normal pregnant women, and nephrin expression on podocytes was evaluated by indirect IF. Unstimulated podocytes showed a surface expression of nephrin in a fine, punctuate pattern with peripheral distribution (Fig. 1A). As shown in Fig. 1, podocyte stimulation with sera from PE patients did not modify the surface expression of nephrin compared with unstimulated cells and with cells stimulated with sera from control pregnant women.

Effects of conditioned medium derived from endothelial cells incubated with sera from PE or normal pregnant women on the expression of nephrin, podocin, and synaptopodin by podocytes. Since endothelial cells are considered the primary target in $\mathrm{PE}$, we tested the hypothesis that a factor(s) produced by
A
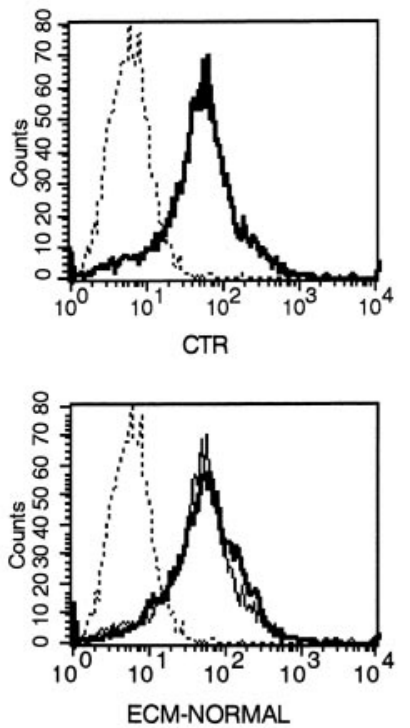

B
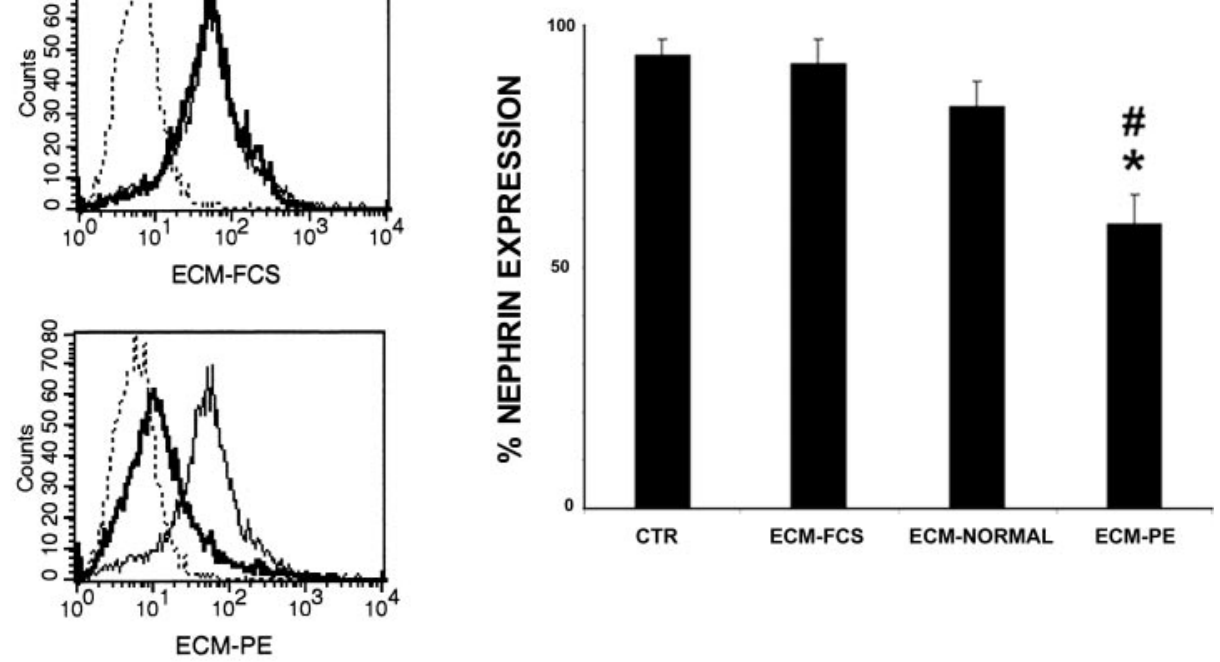

D

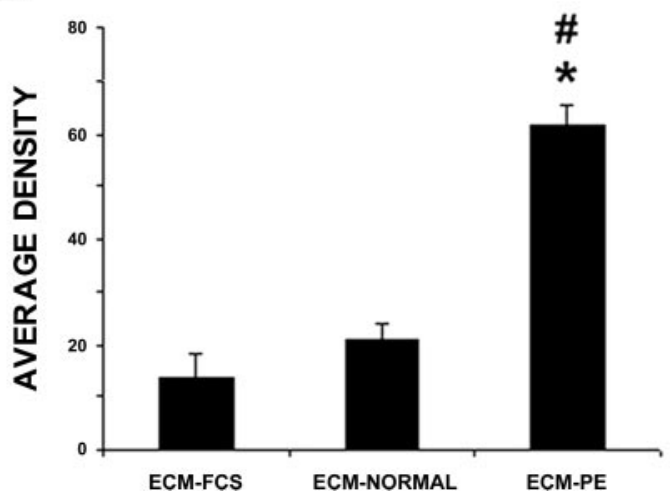

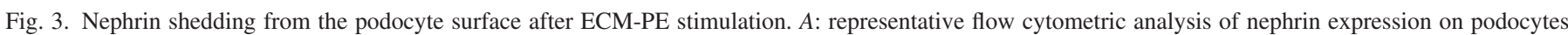

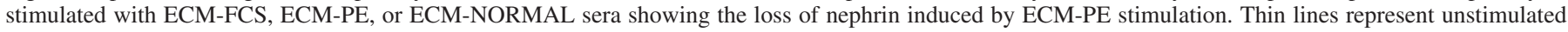

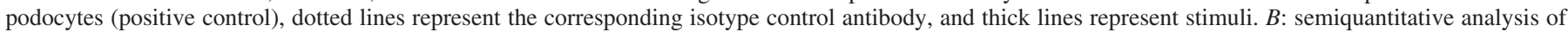

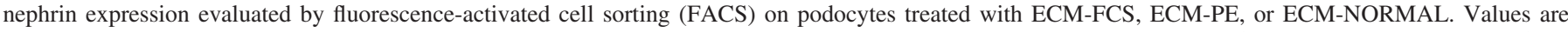

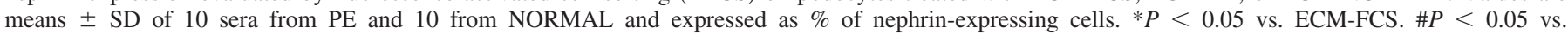

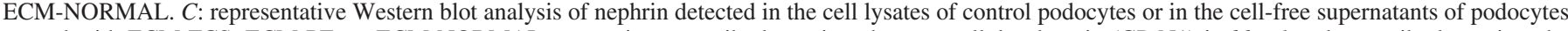

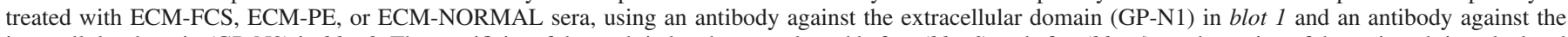

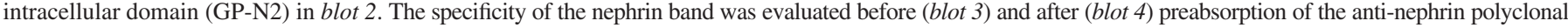

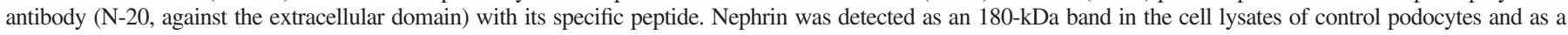

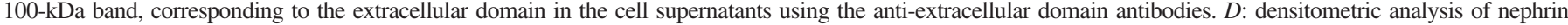

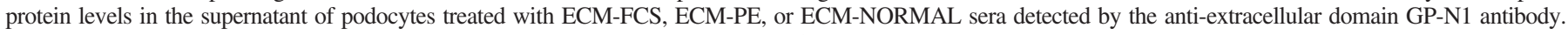
Values are means $\pm \mathrm{SD}$ of 3 different experiments with 3 different sera. $* P<0.05$ vs. ECM-FCS. \#P $<0.01$ vs. ECM-NORMAL. 
glomerular endothelial cells stimulated with PE sera or plasmas may affect the expression of nephrin, podocin, and synaptopodin. For this purpose, glomerular endothelial cells were incubated with $10 \%$ sera or plasmas from PE or normal pregnant women and the ECM was collected after $72 \mathrm{~h}$. Podocytes were then incubated for $1 \mathrm{~h}$ with ECM, and nephrin, podocin, and synaptopodin expression was evaluated. ECM from endothelial cells stimulated with PE sera as well as plasmas (ECM-PE) induced a significant reduction of nephrin expression on the cell surface compared with ECM from endothelial cells incubated with FCS (ECM-FCS) or with sera and plasmas from normal pregnant women (ECM-NORMAL) (Fig. 2, $A$ and $B$ ). In addition, a significant reduction of synaptopodin but not of podocin was observed (Fig. 2C). As seen in Fig. 2A, loss of nephrin was associated with its redistribution as clusters on the podocyte surface.

Nephrin expression was also tested by flow cytofluorimetric analysis that confirmed a significant reduction of nephrin in podocytes stimulated for $1 \mathrm{~h}$ with ECM-PE and not with ECM-NORMAL or ECM-FCS (Fig. 3, $A$ and $B$ ).
The release of nephrin due to podocyte stimulation with ECM-PE was confirmed by Western blot analysis of the cell supernatant. Nephrin, as a 100-kDa fragment, was detected in the podocyte-free supernant using a specific antibody against the extracellular domain (GP-N1), but not with a specific antibody against the intracellular domain (GP-N2) of nephrin (Fig. 3, $C$ and $D)$. These data suggested that ECM-PE stimulus induced a reduction of nephrin expression on the podocyte surface due, at least in part, to shedding of the extracellular domain of this protein.

Endothelial ET-1 production mediates the loss of nephrin induced by ECM-PE. In the attempt to identify a possible factor responsible for nephrin loss in the ECM-PE, we tested the effect of receptor antagonists for ET-1 and angiotensin II, vasoactive mediators known to be involved in PE. Pretreatment of podocytes with an ET-1A receptor antagonist $\left(N\right.$-acetyl-[D-TRP $\left.{ }^{16}\right]-E T 1$, fragment 16-21, $0.4 \mu \mathrm{M})$, markedly reduced nephrin loss induced by ECM-PE stimulation (Fig. $4, A$ and $B$ ). In contrast, cell pretreatment with an angiotensin II receptor antagonist (losartan, $10^{-6} \mathrm{M}$ ) did not show a protective effect on nephrin loss from podocytes (Fig. 4A).

A
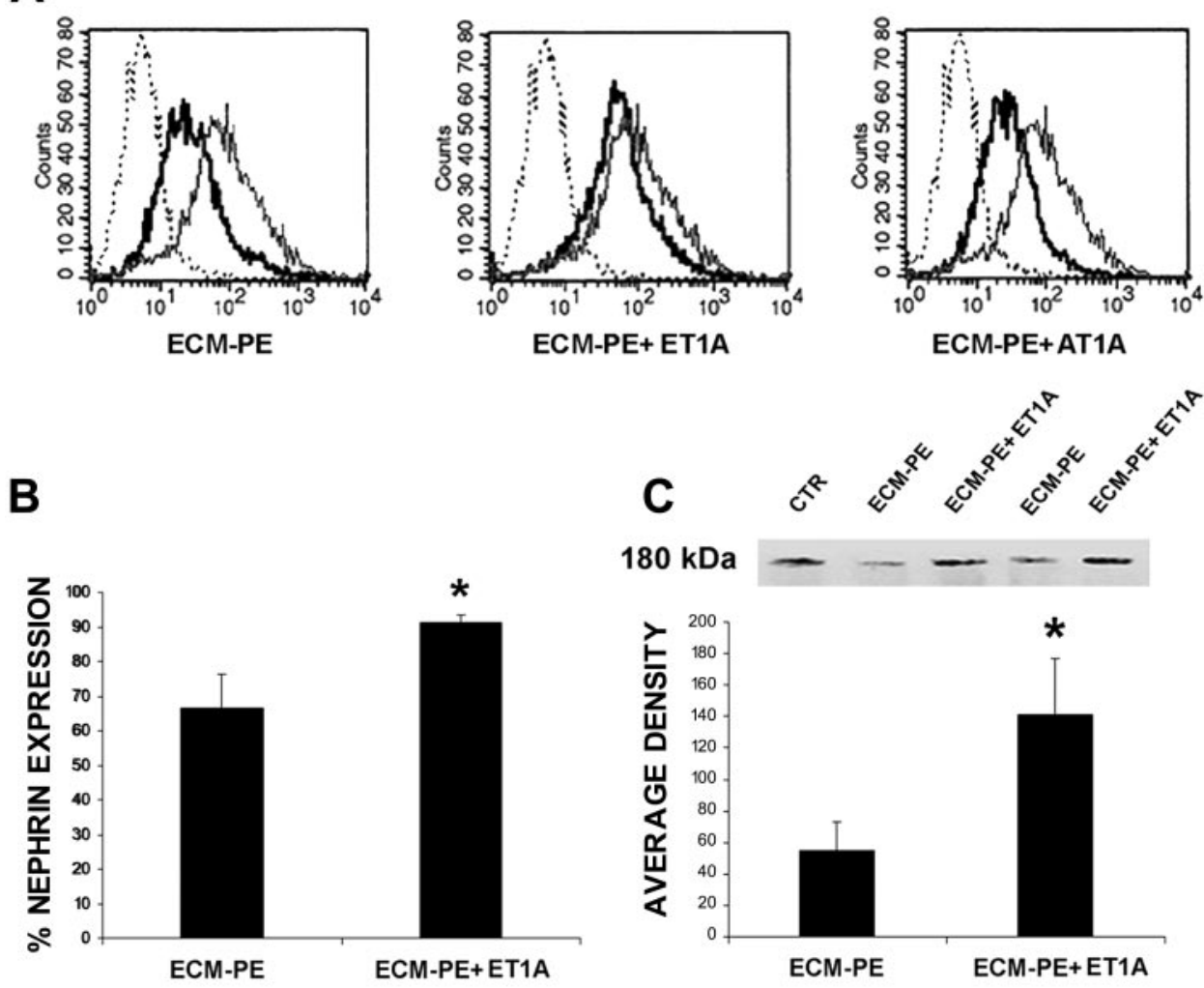

D

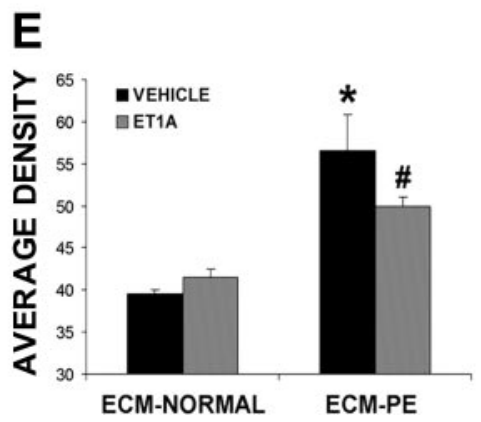

Fig. 4. Treatment with an endothelin-1A (ET1A) receptor antagonist inhibits the effect of ECM-PE on nephrin loss. A: representative cytofluorimetric evaluation of nephrin expression after $1 \mathrm{~h}$ of stimulation with ECM-PE in the absence or presence of an ET-1 receptor antagonist (ET-1A) or an angiotensin II receptor antagonist (AT1A). Nephrin loss by ECM-PE was prevented by ET-1A. Thin lines represent unstimulated podocytes (positive control), dotted lines represent the corresponding isotype control antibody, and thick lines represent stimuli. $B$ : semiquantitative analysis of nephrin expression with flow cytometric analysis of podocytes treated with ECM-PE in the absence or presence of ET-1A. Values are means \pm SD of 5 experiments expressed as $\%$ of nephrin expression. $* P<0.05$ vs. ECMPE. $C$ : immunoprecipitation with an antinephrin polyclonal antibody of the podocyte lysates after 1-h incubation with ECM-PE sera in the absence or presence of ET-1A. The treatment with ET-1A reverses nephrin loss induced by ECM-PE. $* P<0.05$ vs. ECMPE. Values are means \pm SD of 3 different experiments. $D$ : representative Western blot of supernatant of podocytes treated with ECM-NORMAL and ECM-PE sera in the absence or presence of ET-1A. Nephrin was detected with a GP-N1 polyclonal antibody for the extracellular domain as a fragment of $100 \mathrm{kDa}$. E: densitometric analysis by Western blot of nephrin protein levels in the supernatant of podocytes stimulated with ECMNORMAL or ECM-PE sera in the absence (black bars) or presence of ET-1A (gray bars). Values are means \pm SD of 3 different experiments. ${ }^{*} P<0.05$ vs. ECM-NORMAL. $\# P<0.05$ vs. ECM-PE alone. 
These data were confirmed by immunoprecipitation experiments with an anti-nephrin antibody showing the maintenance of cell-associated nephrin on podocyte lysates after cell incubations with ECM-PE in the presence of an ET-1A receptor antagonist with respect to ECM-PE alone (Fig. 4C). In parallel, nephrin was absent in the podocyte supernatant after ECM-PE stimulus in the presence of the ET-1A receptor antagonist, as detected by Western blot analysis (Fig. 4D), suggesting the inhibition of nephrin shedding from the surface of podocytes.

Podocyte treatment with recombinant ET-1 showed loss of nephrin that was prevented by the ET-1A receptor antagonist (Fig. 5A), supporting a possible role of ET-1 released from endothelial cells stimulated by PE sera. Indeed, glomerular endothelial cells released ET-1 after stimulation with PE. As shown in Fig. 5B, ET-1 concentration in the supernatant of cells stimulated with PE serum was significantly enhanced (106 $\pm 9 \mathrm{pg} / 10^{6}$ cells) compared with cells exposed to normal serum $\left(26 \pm 16 \mathrm{pg} / 10^{6}\right.$ cells $)$. This was confirmed by the enhanced expression of ET-1 mRNA by endothelial cells stimulated with PE (Fig. 5C).

As shown for ECM-PE, ET-1 induced redistribution and shedding of nephrin from the surface of podocytes (not shown). This effect was associated with a podocyte cytoskeleton redistribution. Podocytes, when confluent, exhibited a pattern of F-actin filaments distributed as stress fiber bundles along the axis of the cells, as shown by confocal microscopy (Fig. 5D). When stimulated with ECM-PE or ET-1, we observed a loss of stress fibers and F-actin accumulation at the cell periphery compared with control and ECM-NORMAL. Pretreatment of podocytes with a ET-1A receptor antagonist

A
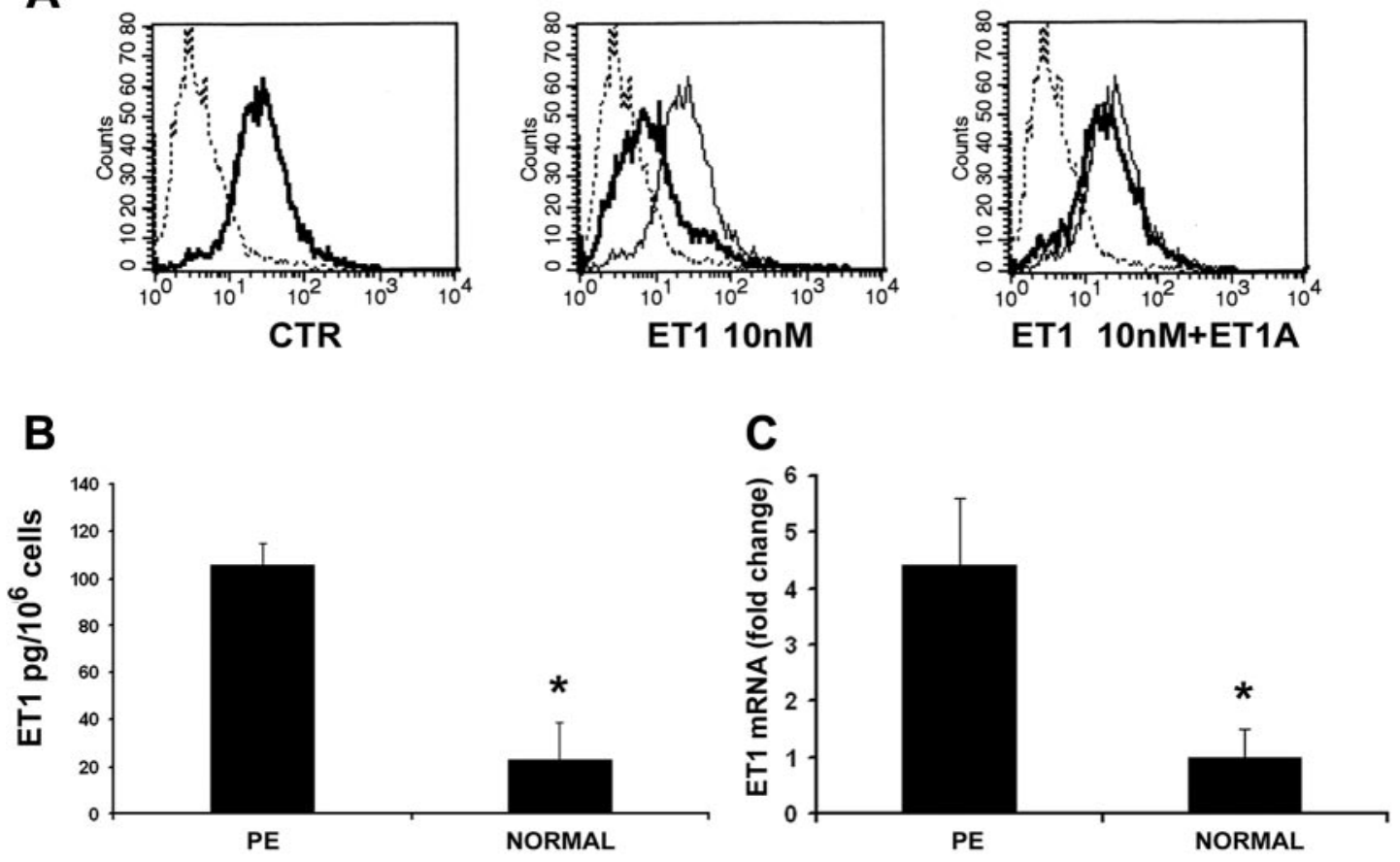

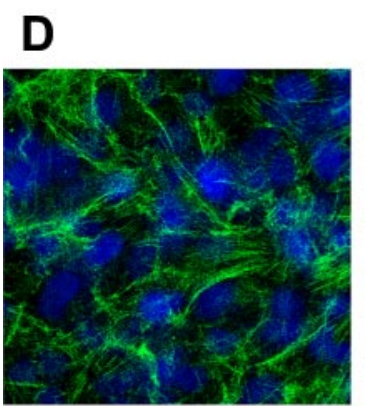

CTR

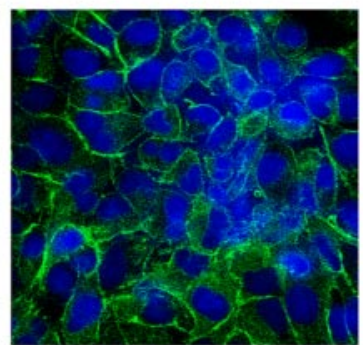

ECM-PE

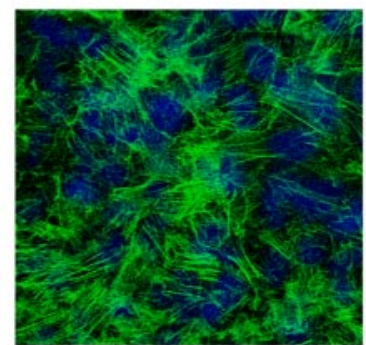

ECM-PE+ET1A

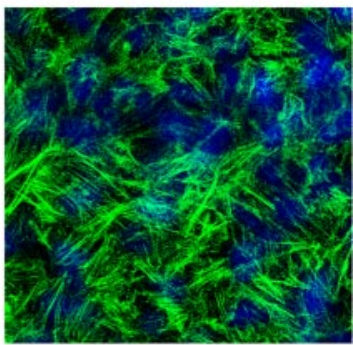

ECM-NORMAL

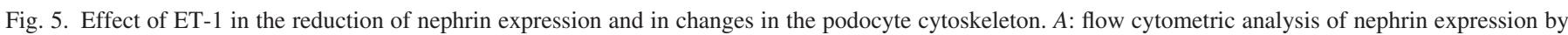

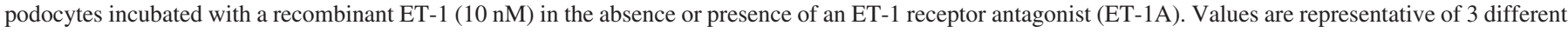

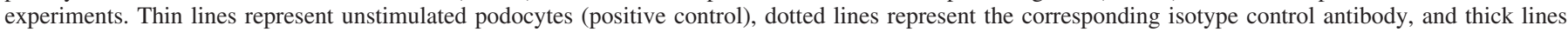

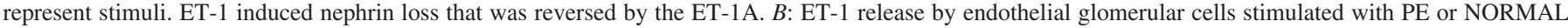

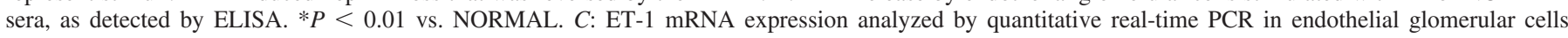

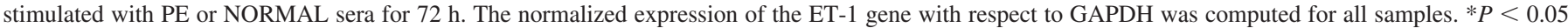

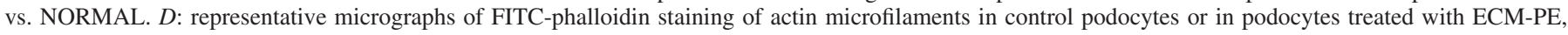

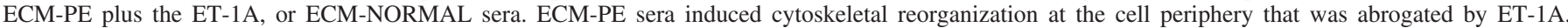

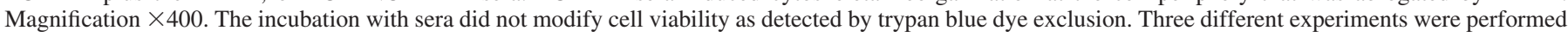
with 5 different PE and NORMAL sera. 
prevented changes in cytoskeleton organization and stress fiber reduction induced by ECM-PE, suggesting that ET-1 stimulates cytoskeleton redistribution (Fig. 5D). Moreover, real-time PCR studies showed ECM-PE or ET-1 did not affect nephrin mRNA levels after 1-h stimulation (Fig. 6A) nor after $24 \mathrm{~h}$ (not shown), indicating that nephrin loss was due to shedding rather then to an altered synthesis. In addition, after 24-h incubation nephrin expression was restored on the podocyte surface (Fig. $6, B$ and $C$ ).

Since a recent study suggested that VEGF blockade is responsible for proteinuria (43) in PE, we evaluated whether blockade of VEGF stimulated ET-1 production from endothelial cells and loss of nephrin induced by the endothelial conditioned medium. As shown in Fig. 7A, blocking an antiVEGF antibody induced a significant production of ET-1 in glomerular endothelial cells. In turn, the conditioned medium

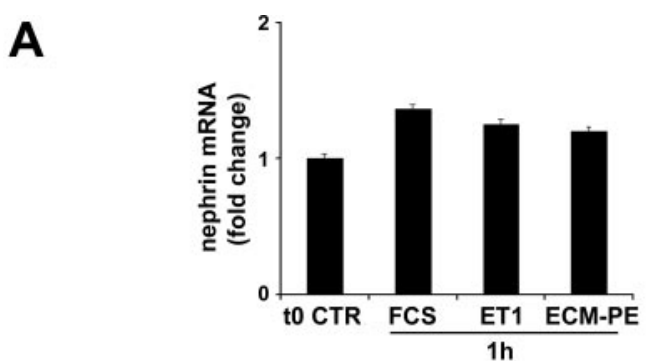

B
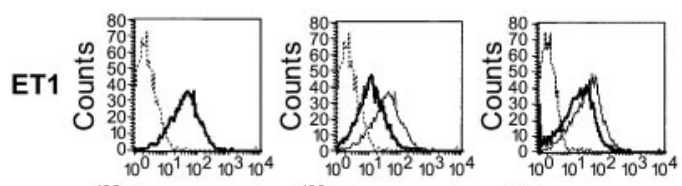

ECM-PE
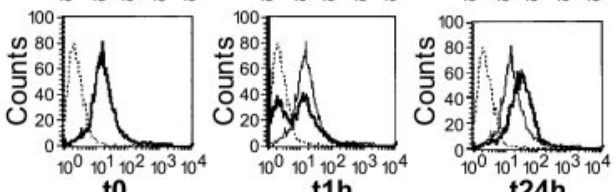

C

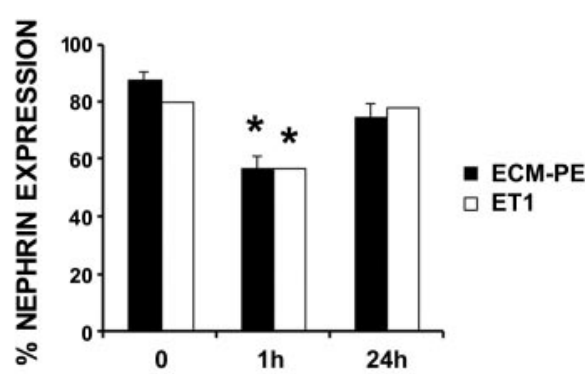

Fig. 6. Nephrin reduction by ECM-PE or ET-1 is transient and does not affect nephrin mRNA levels. A: nephrin mRNA expression analyzed by quantitative real-time PCR in unstimulated podocytes or podocytes stimulated with ECMFCS, ECM-PE, or ET-1 for $1 \mathrm{~h}$. The normalized expression of the nephrin gene with respect to GAPDH was computed for all samples. Values are means \pm SD of 2 independent experiments performed in triplicate and expressed as foldchanges with respect to control. $B$ : representative flow cytometric panels showing the time course of nephrin expression by podocytes treated with ET-1 or ECM-PE. Thin lines represent unstimulated podocytes (positive control), dotted lines represent the corresponding isotype control antibody, and thick lines represent stimuli. Nephrin expression was reacquired at $24 \mathrm{~h}$. C: semiquantitative analysis of nephrin expression by podocytes stimulated with ECM-PE (filled bars) or ET-1 (open bars). Values are means \pm SD of 4 experiments. $* P<0.05$ vs. time 0 .
A

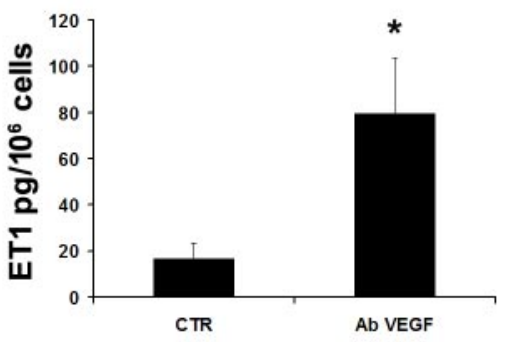

B
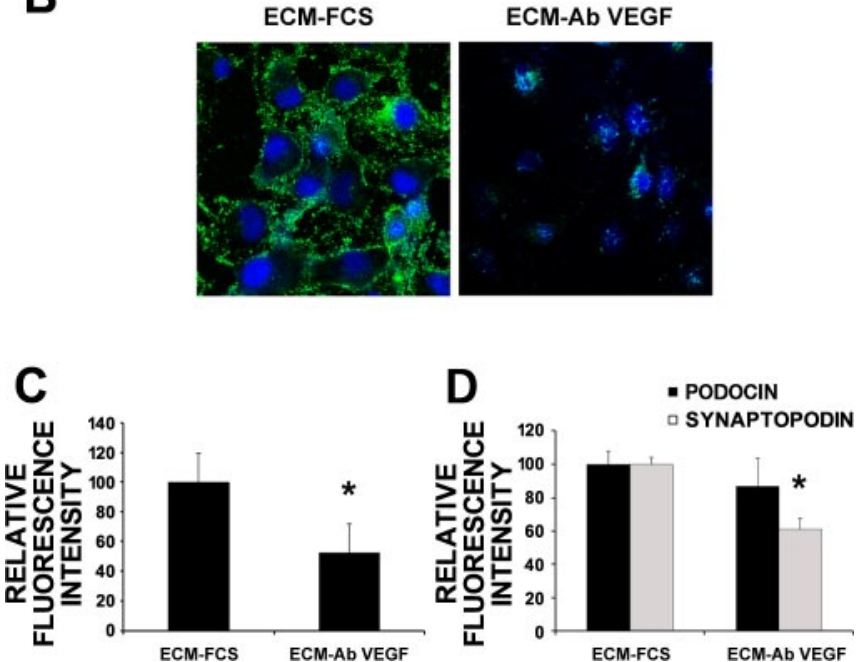

Fig. 7. Effect of VEGF blockade on ET-1 production and slit diaphragm protein expression. A: ET-1 release by endothelial glomerular cells stimulated with anti-VEGF antibody (Ab VEGF), as detected by ELISA. $* P<0.01$ vs. CTR. B: representative micrographs of nephrin expression detected by immunofluorescence in podocytes incubated with ECM derived from glomerular endothelial cells stimulated with anti-VEGF antibody (ECM-Ab VEGF). Nephrin loss was observed in respect to ECM-FCS. $C$ and $D$ : semiquantitative analysis of the expression of nephrin $(C)$, podocin, and synaptopodin $(D)$ evaluated as relative fluorescence intensity after podocyte stimulation with ECM-FCS or ECM-Ab VEGF for $1 \mathrm{~h} . * P<0.05$ vs. ECM-FCS. Values are representative of 5 different experiments.

obtained by endothelial cells after VEGF blockade induced a significant loss of nephrin and synaptopodin, but not podocin from podocytes (Fig. 7, $B-D$ ). No direct effect of the antiVEGF antibody on nephrin and synaptopodin loss was observed (not shown).

Effect of protease inhibitors on expression of nephrin after $E C M-P E$ stimulation. As we have detected nephrin shedding in the cell-free supernatant after ECM-PE stimulation, we analyzed the possible role of proteases as cleaving enzymes of the nephrin extracellular domain.

For this purpose, we tested two metalloproteases inhibitors: GM6001, a collagenase inhibitor, and SB-3CT, a gelatinase inhibitor $(16,21)$. Pretreatment of podocytes with GM6001 or SB-3CT did not induce a reduction of nephrin loss caused by ECM-PE stimulus, as indicated by FACS analysis (Fig. 8A) nor inhibition of nephrin shedding (not shown). In contrast, pretreatment with a generic serine protease inhibitor, PMSF, prevented nephrin reduction induced by ECM-PE stimulus (Fig. 8). We next tested the effect of two more specific serine protease inhibitors, $\alpha 1$-anti-trypsin and anti-protease inhibitor (anti-PI), on nephrin reduction induced by the ECM-PE stimulus. 
A

Fig. 8. Serine protease inhibitors block nephrin reduction induced by ECM-PE. A: representative flow cytometric panels of nephrin expression by podocytes untreated or treated with ECM-PE or ET-1 in the absence or presence of 3 different serine protease inhibitors [PMSF, $\alpha_{1}$-anti-trypsin, and anti-protease inhibitor (PI)] or 2 specific metalloprotease inhibitors (GM6001 and SB-3CT). Thin lines represent unstimulated podocytes (positive control), dotted lines represent the corresponding isotype control antibody, and thick lines represent stimuli Treatment with serine proteases but not with metalloproteases inhibitors prevented the reduction in nephrin loss. $B$ : semiquantitative analysis of nephrin expression by podocytes stimulated with ECM-PE (filled bars) or ET-1 (open bars). Values are means \pm SD of 5 experiments expressed as \% of nephrin expression. ${ }^{*} P<0.05$ vs. ECM-PE and ET- 1 alone.

B
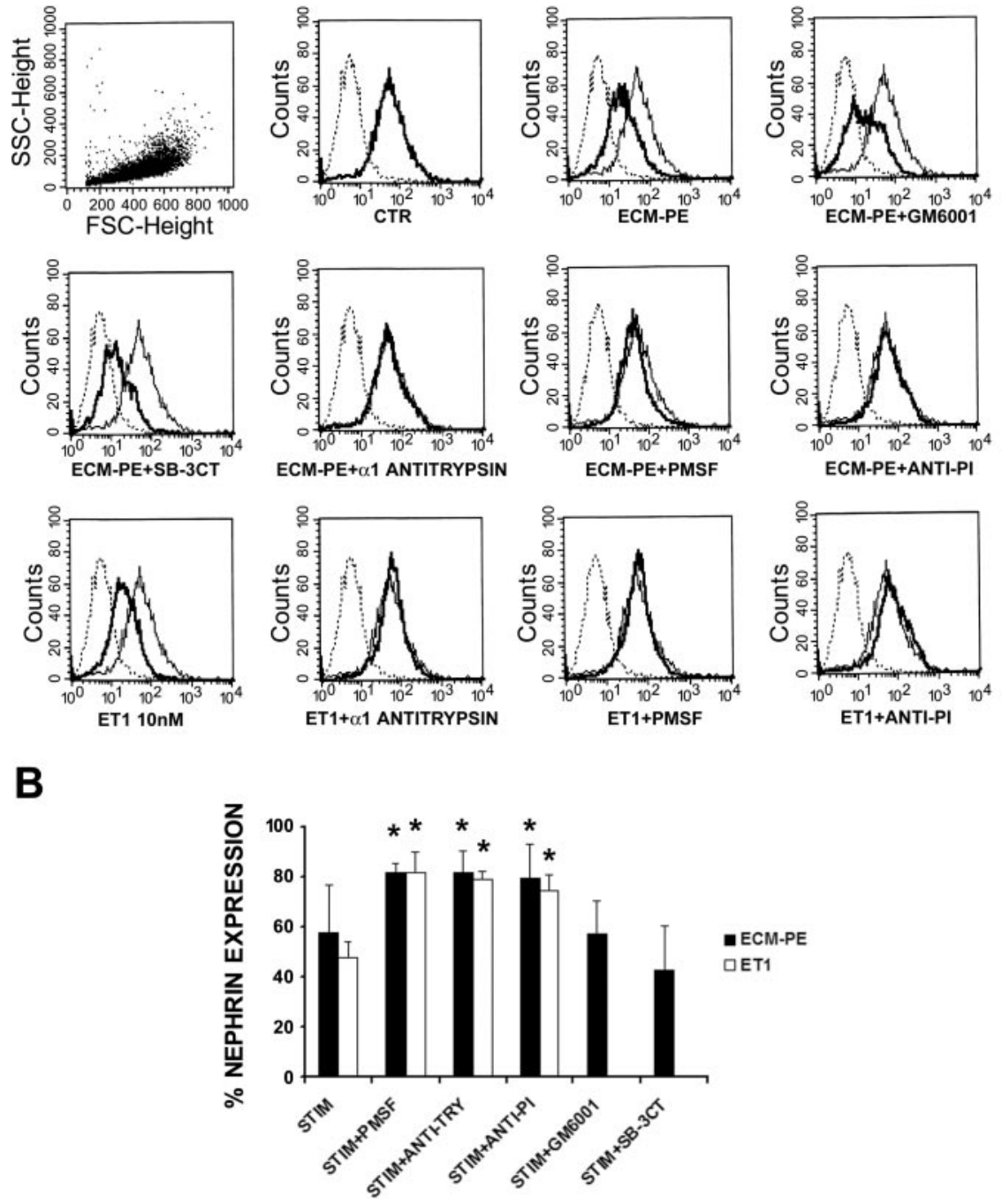

Podocyte treatment with anti-PI $(5-10 \mu \mathrm{g} / \mathrm{ml})$ and $\alpha 1$-antitrypsin $(5 \mu \mathrm{g} / \mathrm{ml})$ (5) before ECM-PE addition induced a marked inhibition of nephrin loss (Fig. 8), suggesting that nephrin shedding is mediated by specific serine proteases activated in podocytes after ECM-PE stimulation.

Moreover, podocytes pretreated with PMSF, $\alpha 1$-anti-trypsin, and anti-PI before recombinant ET-1 stimulus showed the same reduction of nephrin loss (Fig. 8), confirming that the effect of ET-1 on nephrin shedding was mediated by serine protease release.

\section{DISCUSSION}

In the present study, we showed that sera as well as plasmas from patients with PE downregulated the expression of nephrin by inducing ET-1 release from endothelial cells. The loss of nephrin from the podocyte membrane induced by ET-1 was associated with cytoskeletal activation and due to protease activation, leading to its cleavage from the cell membrane and shedding into the cell supernatant.

Increased maternal vascular permeability and enhanced vasoconstriction are major underlying pathophysiological events in PE $(17,38)$. Clinically, proteinuria, and interstitial edema are mainly considered manifestations of endothelial dysfunction. In this context, a number of studies have confirmed that sera from PE women cause endothelial cell activation $(2,37)$. However, no information is present on the effect of PE factors on the slit diaphragm of podocytes. We and others recently showed that nephrin expression is reduced in glomeruli of patients with primary acquired nephritic syndrome, including membranous glomerulonephritis (GN), minimal-change GN, and focal segmental glomerulosclerosis, as well as in diabetic patients with proteinuria $(9-11)$. In some, but not in all, of these diseases, the altered expression of slit diaphragm proteins is related to primary mutations. It is debated whether the loss of nephrin and related proteins is the cause or the consequence of proteinuria; however, experimental studies of nephrin redistribution induced by antibodies (44) suggest that a cytoskeleton-dependent shedding of nephrin may be instrumental in inducing proteinuria. Although a severe foot process effacement has not been documented in PE, a recent report showed that the expression of the glomerular proteins of the slit membrane nephrin and synaptopodin was reduced in patients with PE (13). Sugimoto et al. (43) in an experimental model of PE based on VEGF blockade found occasional but significant 
damage in podocytes. Recently, urinary podocyte excretion has been reported in PE with a predictive value (14). Taken together, these data indicate that an alteration of slit diaphragm proteins could also be relevant in the pathogenesis of proteinuria in PE. In the present study, we showed that PE sera did not exert a direct effect on nephrin loss from the podocyte surface. We therefore investigated the possibility that sera and plasma from patients with PE stimulate the release of endothelial factors able to cross the basal membrane and to affect nephrin expression on podocytes. Indeed, endothelial dysfunction has a primary role in the pathogenesis of $\mathrm{PE}(17,38)$. Recent studies indicate that decrease in free VEGF due to the presence of soluble VEGFR-1 (sFlt-1) in the sera of PE patients may account for such endothelial dysfunction (25). Moreover, the infusion of sFlt-1 in pregnant rats induced hypertension, proteinuria, and glomerular endotheliosis (43). In the present study, we found that VEGF blockade did not directly induce nephrin loss from podocytes. Indeed, podocytes do not express the VEGF receptor $(12,41)$; thus it is conceivable that the in vivo observed effect of VEGF blockade on podocytes may be indirect (43). In support of an indirect mechanism of proteinuria, we found that sera from PE patients stimulated the release of an endothelial factor/s able to trigger the loss of nephrin and synaptopodin from cultured human podocytes. We previously demonstrated that angiotensin II is able to induce nephrin loss (11). However, inhibitors of the angiotensin II receptor did not prevent the effect of the endothelial factor/s elicited by PE sera. Searching for the possible mediator, we found that ET-1 was responsible for the loss of nephrin as this was abrogated by an ET-1 receptor inhibitor. ET-1, a potent endogenous vasoconstrictor peptide, has been previously shown to be released from endothelial cells in PE (29). Indeed, sera from pregnant rats with decreased uterine perfusion induced ET-1 release from endothelial cells (39). In our study, we found that PE sera induced ET-1 production by glomerular endothelial cells and that the administration of recombinant ET-1 to podocytes, which are known to express the ET-1 receptor $(26,27,33)$, triggered the loss of nephrin. Moreover, we found that VEGF blockade stimulated production of ET-1 by endothelial cells that, in turn, may induce nephrin and synaptopodin loss from podocytes. The data of the present study indicate that in PE circulating factors, such as sFlt1 or cytokines, may cause an endothelial activation able to locally affect podocyte homeostasis.

The loss of nephrin was not due to an inhibition of its synthesis, but rather to shedding from the cell surface. A similar reduction of surface expression was observed for synaptopodin, but not for podocin, which presents an intracellular $\mathrm{NH}_{2}$ and $\mathrm{COOH}$ terminal $(19,20)$. The shedding of surface molecules is known to depend on their redistribution on the plasma membrane and the cleavage of their extracellular portion. Several mediators were reported to induce nephrin shedding by activation of the cell cytoskeleton and by cleavage of the extracellular domain $(3,10,11)$. In PE, this mechanism is probably shared by ET-1, which was able to induce nephrin loss and in parallel acted on cytoskeletal redistribution. This suggests that the activation of the cell cytoskeleton modifies surface expression of nephrin, thus allowing its dislocation from the plasma membrane to an extracellular site. Indeed, it has been shown that nephrin is linked to the actin cytoskeleton and dissociates from actin in early experimental membranous nephropathy $(40,47)$. It has been previously shown that Neph2, a slit diaphragm component, is cleaved from the podocyte surface by metalloproteases (16). However, in our experimental condition, nephrin shedding was not dependent on metalloprotease, but rather on serine protease activation.

In conclusion, this study identifies a mechanism of nephrin loss that may account for the enhanced glomerular permeability in PE. A serum factor or factors present in PE patients trigger the production of ET-1 from glomerular endothelial cells and ET-1 in turn may induce shedding of nephrin from the surface of podocytes. These results suggest that interfering with ET-1 or nephrin shedding may inhibit proteinuria.

\section{GRANTS}

This work was supported by the Italian Ministry of University and Research (MIUR) COFIN and ex60\% and by the Italian Ministry of Health (Ricerca Finalizzata 02), Regione Piemonte.

\section{REFERENCES}

1. American College of Obstetricians, and Gynecologists. ACOG practice bulletin. Diagnosis and management of preeclampsia and eclampsia. Number 33, January 2002. Int J Gynaecol Obstet 77: 67-75, 2002.

2. Baker PN, Davidge ST, Barankiewicz J, Roberts JM. Plasma of preeclamptic women stimulates and then inhibits endothelial prostacyclin. Hypertension 27: 56-61, 1996.

3. Bussolati B, Deregibus MC, Fonsato V, Doublier S, Spatola T, Procida S, Di Carlo F, Camussi G. Statins prevent oxidized LDL-induced injury of glomerular podocytes by activating the phosphatidylinositol 3-kinase/ AKT-signaling pathway. J Am Soc Nephrol 16: 1936-1947, 2005.

4. Bussolati B, Grange C, Bruno S, Buttiglieri S, Deregibus MC, Tei L, Aime S, Camussi G. Neural-cell adhesion molecule (NCAM) expression by immature and tumor-derived endothelial cells favors cell organization into capillary-like structures. Exp Cell Res 312: 913-924, 2006.

5. Camussi G, Tetta C, Bussolino F, Baglioni C. Synthesis and release of platelet-activating factor is inhibited by plasma alpha 1-proteinase inhibitor or alpha 1-antichymotrypsin and is stimulated by proteinases. $J$ Exp Med 168: 1293-1306, 1988.

6. Conaldi PG, Biancone L, Bottelli A, De Martino A, Camussi G, Toniolo A. Distinct pathogenic effects of group B coxsackieviruses on human glomerular and tubular kidney cells. J Virol 71: 9180-9187, 1997.

7. D'Antona D, Reis FM, Benedetto C, Evans LW, Groome NP, de Kretser DM, Wallace EM, Petraglia F. Increased maternal serum activin A but not follistatin levels in pregnant women with hypertensive disorders. J Endocrinol 165: 157-162, 2000.

8. Deregibus MC, Cantaluppi V, Doublier S, Brizzi MF, Deambrosis I, Albini A, Camussi G. HIV-1-Tat protein activates phosphatidylinositol 3-kinase/AKT-dependent survival pathways in Kaposi's sarcoma cells. J Biol Chem 277: 25195-25202, 2002.

9. Doublier S, Musante L, Lupia E, Candiano G, Spatola T, Caridi G, Zennaro C, Carraro M, Ghiggeri GM, Camussi G. Direct effect of plasma permeability factors from patients with idiopathic FSGS on nephrin and podocin expression in human podocytes. Int J Mol Med 16: 49-58, 2005

10. Doublier S, Ruotsalainen V, Salvidio G, Lupia E, Biancone L, Conaldi PG, Reponen P, Tryggvason K, Camussi G. Nephrin redistribution on podocytes is a potential mechanism for proteinuria in patients with primary acquired nephrotic syndrome. Am J Pathol 158: 1723-1731, 2001.

11. Doublier S, Salvidio G, Lupia E, Ruotsalainen V, Verzola D, Deferrari G, Camussi G. Nephrin expression is reduced in human diabetic nephropathy: evidence for a distinct role for glycated albumin and angiotensin II. Diabetes 52: 1023-1030, 2003.

12. Feng D, Nagy JA, Brekken RA, Pettersson A, Manseau EJ, Pyne K, Mulligan R, Thorpe PE, Dvorak HF, Dvorak AM. Ultrastructural localization of the vascular permeability factor/vascular endothelial growth factor (VPF/VEGF) receptor-2 (FLK-1, KDR) in normal mouse kidney and in the hyperpermeable vessels induced by VPF/VEGF-expressing tumors and adenoviral vectors. J Histochem Cytochem 48: 545-556, 2000 .

13. Garovic VD, Wagner SJ, Petrovic LM, Gray CE, Hall P, Sugimoto H, Kalluri R, Grande JP. Glomerular expression of nephrin and synaptopo- 
din, but not podocin, is decreased in kidney sections from women with preeclampsia. Nephrol Dial Transplant 22: 1136-1143, 2007.

14. Garovic VD, Wagner SJ, Turner ST, Rosenthal DW, Watson WJ, Brost BC, Rose CH, Gavrilova L, Craigo P, Bailey KR, Achenbach J, Schiffer M, Grande JP. Urinary podocyte excretion as a marker for preeclampsia. Am J Obstet Gynecol 196: 320 e321-327, 2007.

15. Gerke P, Huber TB, Sellin L, Benzing T, Walz G. Homodimerization and heterodimerization of the glomerular podocyte proteins nephrin and NEPH1. J Am Soc Nephrol 14: 918-926, 2003.

16. Gerke P, Sellin L, Kretz O, Petraschka D, Zentgraf H, Benzing T, Walz G. NEPH2 is located at the glomerular slit diaphragm, interacts with nephrin and is cleaved from podocytes by metalloproteinases. J Am Soc Nephrol 16: 1693-1702, 2005.

17. Granger JP, Alexander BT, Llinas MT, Bennett WA, Khalil RA. Pathophysiology of hypertension during preeclampsia linking placental ischemia with endothelial dysfunction. Hypertension 38: 718-722, 2001.

18. He Y, Smith SK, Day KA, Clark DE, Licence DR, Charnock-Jones DS. Alternative splicing of vascular endothelial growth factor (VEGF)-R1 (FLT-1) pre-mRNA is important for the regulation of VEGF activity. Mol Endocrinol 13: 537-545, 1999.

19. Johnstone DB, Holzman LB. Clinical impact of research on the podocyte slit diaphragm. Nat Clin Pract Nephrol 2: 271-282, 2006.

20. Kawachi H, Miyauchi N, Suzuki K, Han GD, Orikasa M, Shimizu F. Role of podocyte slit diaphragm as a filtration barrier. Nephrology (Carlton) 11: 274-281, 2006.

21. Ke Z, Lin H, Fan Z, Cai TQ, Kaplan RA, Ma C, Bower KA, Shi X, Luo J. MMP-2 mediates ethanol-induced invasion of mammary epithelial cells over-expressing ErbB2. Int J Cancer 119: 8-16, 2006.

22. Kendall RL, Thomas KA. Inhibition of vascular endothelial cell growth factor activity by an endogenously encoded soluble receptor. Proc Natl Acad Sci USA 90: 10705-10709, 1993.

23. Kestila M, Lenkkeri U, Mannikko M, Lamerdin J, McCready $\mathbf{P}$, Putaala H, Ruotsalainen V, Morita T, Nissinen M, Herva R, Kashtan CE, Peltonen L, Holmberg C, Olsen A, Tryggvason K. Positionally cloned gene for a novel glomerular protein-nephrin-is mutated in congenital nephrotic syndrome. Mol Cell 1: 575-582, 1998.

24. Lenkkeri U, Mannikko M, McCready P, Lamerdin J, Gribouval O, Niaudet PM, Antignac CK, Kashtan CE, Homberg C, Olsen A, Kestila M, Tryggvason K. Structure of the gene for congenital nephrotic syndrome of the Finnish type (NPHS1) and characterization of mutations. Am J Hum Genet 64: 51-61, 1999.

25. Maynard SE, Min JY, Merchan J, Lim KH, Li J, Mondal S, Libermann TA, Morgan JP, Sellke FW, Stillman IE, Epstein FH, Sukhatme VP, Karumanchi SA. Excess placental soluble fms-like tyrosine kinase 1 (sFlt1) may contribute to endothelial dysfunction, hypertension, and proteinuria in preeclampsia. J Clin Invest 111: 649-658, 2003.

26. Morigi M, Buelli S, Angioletti S, Zanchi C, Longaretti L, Zoja C, Galbusera M, Gastoldi S, Mundel P, Remuzzi G, Benigni A. In response to protein load podocytes reorganize cytoskeleton and modulate endothelin-1 gene: implication for permselective dysfunction of chronic nephropathies. Am J Pathol 166: 1309-1320, 2005.

27. Morigi M, Buelli S, Zanchi C, Longaretti L, Macconi D, Benigni A, Moioli D, Remuzzi G, Zoja C. Shigatoxin-induced endothelin-1 expression in cultured podocytes autocrinally mediates actin remodeling. Am J Pathol 169: 1965-1975, 2006.

28. Muratovska A, Zhou C, He S, Goodyer P, Eccles MR. Paired-Box genes are frequently expressed in cancer and often required for cancer cell survival. Oncogene 22: 7989-7997, 2003.

29. Nishikawa S, Miyamoto A, Yamamoto H, Ohshika H, Kudo R. Preeclamptic serum enhances endothelin-converting enzyme expression in cultured endothelial cells. Am J Hypertens 14: 77-83, 2001.
30. Ortmann J, Amann K, Brandes RP, Kretzler M, Munter K, Parekh N, Traupe T, Lange M, Lattmann T, Barton M. Role of podocytes for reversal of glomerulosclerosis and proteinuria in the aging kidney after endothelin inhibition. Hypertension 44: 974-981, 2004.

31. Page NM, Lowry PJ. Is 'pre-eclampsia' simply a response to the side effects of a placental tachykinin? J Endocrinol 167: 355-361, 2000.

32. Petraglia F, Luisi S, Benedetto C, Zonca M, Florio P, Casarosa E, Volpe A, Bernasconi S, Genazzani AR. Changes of dimeric inhibin B levels in maternal serum throughout healthy gestation and in women with gestational diseases. J Clin Endocrinol Metab 82: 2991-2995, 1997.

33. Rebibou JM, He CJ, Delarue F, Peraldi MN, Adida C, Rondeau E, Sraer JD. Functional endothelin 1 receptors on human glomerular podocytes and mesangial cells. Nephrol Dial Transplant 7: 288-292, 1992.

34. Redman CW. Current topic: pre-eclampsia and the placenta. Placenta 12: 301-308, 1991.

35. Redman CW, Sargent IL. Latest advances in understanding preeclampsia. Science 308: 1592-1594, 2005.

36. Roberts JM, Cooper DW. Pathogenesis and genetics of pre-eclampsia. Lancet 357: 53-56, 2001.

37. Roberts JM, Edep ME, Goldfien A, Taylor RN. Sera from preeclamptic women specifically activate human umbilical vein endothelial cells in vitro: morphological and biochemical evidence. Am J Reprod Immunol 27: 101-108, 1992.

38. Roberts JM, Lain KY. Recent Insights into the pathogenesis of preeclampsia. Placenta 23: 359-372, 2002.

39. Roberts L, LaMarca BB, Fournier L, Bain J, Cockrell K, Granger JP. Enhanced endothelin synthesis by endothelial cells exposed to sera from pregnant rats with decreased uterine perfusion. Hypertension 47: 615618, 2006.

40. Saran AM, Yuan H, Takeuchi E, McLaughlin M, Salant DJ. Complement mediates nephrin redistribution and actin dissociation in experimental membranous nephropathy. Kidney Int 64: 2072-2078, 2003.

41. Simon M, Rockl W, Hornig C, Grone EF, Theis H, Weich HA, Fuchs E, Yayon A, Grone HJ. Receptors of vascular endothelial growth factor/ vascular permeability factor (VEGF/VPF) in fetal and adult human kidney: localization and $\left[{ }^{125} \mathrm{I}\right] \mathrm{VEGF}$ binding sites. J Am Soc Nephrol 9: 1032-1044, 1998.

42. Stepan H, Faber R, Dornhofer N, Huppertz B, Robitzki A, Walther T. New insights into the biology of preeclampsia. Biol Reprod 74: 772-776, 2006.

43. Sugimoto H, Hamano Y, Charytan D, Cosgrove D, Kieran M, Sudhakar A, Kalluri R. Neutralization of circulating vascular endothelial growth factor (VEGF) by anti-VEGF antibodies and soluble VEGF receptor 1 (sFlt-1) induces proteinuria. J Biol Chem 278: 12605-12608, 2003.

44. Topham PS, Kawachi H, Haydar SA, Chugh S, Addona TA, Charron KB, Holzman LB, Shia M, Shimizu F, Salant DJ. Nephritogenic mAb 5-1-6 is directed at the extracellular domain of rat nephrin. $J$ Clin Invest 104: 1559-1566, 1999.

45. Vuorela P, Helske S, Hornig C, Alitalo K, Weich H, Halmesmaki E. Amniotic fluid-soluble vascular endothelial growth factor receptor-1 in preeclampsia. Obstet Gynecol 95: 353-357, 2000.

46. Walker JJ. Pre-eclampsia. Lancet 356: 1260-1265, 2000.

47. Yuan H, Takeuchi E, Taylor GA, McLaughlin M, Brown D, Salant DJ. Nephrin dissociates from actin, and its expression is reduced in early experimental membranous nephropathy. J Am Soc Nephrol 13: 946-956, 2002.

48. Zanone MM, Favaro E, Doublier S, Lozanoska-Ochser B, Deregibus MC, Greening J, Huang GC, Klein N, Cavallo Perin P, Peakman M, Camussi G. Expression of nephrin by human pancreatic islet endothelial cells. Diabetologia 48: 1789-1797, 2005. 